\title{
Using Modern Educational Technology to Promote Teaching
}

\section{Modernization}

\author{
Liu Jin-guang ${ }^{1}$ Chen $\mathrm{Xi}^{2}$ \\ ${ }^{1}$ Training Department, Border Control College of Public Security, Guangzhou, China \\ ${ }^{2}$ Department of Administrative Affairs, Border Control College of Public Security, Guangzhou, China \\ 13149377788@163.com_1805756081qq.com
}

Keywords: Modern educational technology; teaching ideas; modern educational teaching Abstract: Institutions of modern teaching, including modern teaching methods and modern teaching ideas. The modern educational technology mainly reflects modern teaching methods, but also promotes the modernization of teaching ideas of powerful driving force. Due to the extensive use of modern educational technology in teaching, it can effectively promote the teaching ideas, reform of teaching content, promoting the update of teaching methods and reforming the traditional teaching model to a large extent, to achieve the diversification of learning, body and socialization. Therefore, full use of modern educational technology and promoting the teaching of modern would be the work priorities and goals of educational and technical workers .

\section{Grasp the meaning of modern educational technology to establishing a good running system for teaching modern}

Modern educational technology is the use of modern educational theory and modern information technology, through the teaching process and teaching resources in design, development, application, management and evaluation, in order to achieve optimization of the theory and practice of teaching. The nature of educational technology center is to undertake complex functions of institutions of educational technology management, education, security and research work in institutions, whose mission is to research, extension, universal use of modern educational technology to optimize the teaching process, to develop and utilization of teaching resources and promoting teaching reform, to improve teaching quality and efficiency, and to promote the modernization of teaching. And it should establish a good operational mechanism for teaching modern in the following aspects.

First, the design of the teaching process and teaching resources. With the enhancement of the teaching content, teaching media updates, reducing teaching hours, higher training quality of personnel requirements, making the contradictions more obvious in the teaching process of implementation each day, which requires colleges and universities teaching staff based on the learning needs analysis, coming up with the best solution to solve the problem, in order to improve the effectiveness of teaching. Educational Technology Workers should know how to make the dominance of teachers and the main role of students into full play, how to select instructional media based on appropriate teaching content, to improve the efficiency and effectiveness of information transfer among education, to provide theoretical guidance and technical support of the media.

Second is the development of the teaching process of teaching resources. As an educational technology center intelligence agencies to actively encourage the teacher to accordance with the 
present difficulties and focus on content in subject knowledge, the preparation of the corresponding series of educational software, and provide technical support and service from beginning to end for them. For the difficult development of teaching materials in slide materials, projection materials, audio-visual materials, multimedia course ware, teachers should be personally involved in guiding and production. Whenever they meet important software development, it is necessary to organize collective research. In addition, they should collect suitable information and teaching resources of related professional institutions to provide services for the discipline teacher.

Third, the teaching process and teaching resources applications. Design, development are to apply, in order to train highly qualified personnel in this objective, rather than to "watch" and "competition." In the new teaching environment, teachers want to make use of modern educational technology, will use modern technology to achieve full use of modern educational technology to mobilize teachers' enthusiasm for teaching. Educational technology workers, on the one hand to provide our teachers with good application of the hardware environment, on the other hand to establish the appropriate incentives. It is the only way to ensure the development of modern education technology on a healthy track.

Fourth, the management of the teaching process and teaching resources. Education Technology Center should manage slide projector, audiovisual media, computer multimedia, computer network teaching in unify and should plan, organize, coordinate and control its process. Take all the teaching information resources collected classified, such as audio-visual materials, multimedia course ware, product parts, they all need establish a web page, which we can enter information online and establish teaching resource library. Strive to teaching digital information processing, storage disc technology, multimedia display, transmission network, information organization nonlinear forward, and ultimately make learning resource serialization, the teaching process and the teaching of intelligent management modernization objectives come true.

Fifth, the teaching process and teaching resources evaluation. Education Technology Center is not only responsible for the development of educational and technical institutions development plans and annual plans, carrying out the work to guide educational technology, research and demonstration of educational technology resolved technical issues related to the development of education in, but also on the use of modern educational technology teacher evaluate the effect. By evaluating, feed-backing teaching process and spreading implementation effect of teaching resources, so as to continuously enrich teaching resources for teachers, improve teaching programs, to optimize the teaching process, the purpose of improving the quality of teaching. Meanwhile we should find the typical thing in evaluation, summing up experience, to make it a strong impetus to modern educational institutions to carry out technical work.

\section{Second, give full play to the advantages of modern educational technology, and create a good teaching environment for the teaching modernization.}

The new situation and tasks have given new meaning to the modern educational technology, and put forward new requirements. Therefore, it is necessary to increase effectively investment further to play the advantage of modern educational technology, and to create a good teaching environment for the teaching modernization.

Strengthening the construction of facilities is the prerequisite for the development of modern educational technology.

Development and application of modern educational technology in teaching require certain substantial condition. Due to the continual maturity of the network technology, communication technology and multimedia technology, multimedia contributes to construction of teaching 
classroom facilities, playing a more and more important role in the modern teaching.

In recent years, college multimedia combination teaching environment is basically sound, but there is a certain gap between computer multimedia teaching conditions and the talent cultivation target and modernization requirements of teaching. Such as the teachers lacking sufficient computer to make course ware, lacking computer multimedia demonstration classroom, and insufficient computer network classroom. Those objectively affect the enthusiasm of the teachers using modern educational technology, and also hinder the process of modernization of teaching in a certain extent.

Therefore, first of all ,to provide sufficient equipment of teaching resources development for teachers, to mobilize their enthusiasm and creativity. Second, to provide teachers with modern places owning teaching means and upgrade configuration gradually regarded as the financial situation. The first step, to construct more Multimedia Classrooms of independent presentation (usually a multimedia computer, a TV screen display instrument, and a large screen projector). The second step, to connect the computer network of multimedia classroom and campus network, forming teaching resources sharing system, which is more convenient for teachers. The third step, to build a interactive network classroom, and eventually engender the display network learning environment in order to achieve the teaching aim of autonomy, interaction, sharing.

\section{Improving the quality of personnel is the key to play the advantages of modern educational technology.}

If not compatible with the modern education idea, knowledge and talents owning technological quality, advanced teaching equipment can only become a kind of decoration and embellishment, which is so called the development of modern educational technology. Now professional educational and technical workers used to be in the audio-visual work of staff. Because of lack of knowledge about the computer multimedia technology, especially network technology knowledge, the development of modern educational technology will be affected in a certain extent.

There are three solutions. First is to introduce talents actively and enrich professional team; second is to send out the workers to be trained and expand professional knowledge; third is on-the-job training to improve their professional skills. Only in this way, can the subject teachers using modern educational technology be guided effectively.

\section{Establishing incentive mechanism is the grantee to play the advantages of modern educational technology.}

"Modern education technology is the commanding point of the current education. Whoever seizes the hill, he will be in a favorable position in the new century." Due to the small number of comrades knows that a little, lack the sense of urgency, combined that the development and application of modern educational technology is a system innovation task which is difficult in some extent, teaching workload is enlarged, and we need to add additional preparation time to teachers. If that is improper handled, the teachers' enthusiasm will be broken, then affecting the playing of the advantage of modern educational technology.

Therefore, it is necessary to develop the relevant incentive mechanism, such as audio-visual materials, multimedia course ware and other modern educational resources; and the media development and application should be included in the workload of teachers teaching properly ; at the end of the year, curriculum evaluation, excellent teachers, and high-quality courses should be also included as important conditions, and the outstanding units and individuals should be rewarded; the important selected topics can also be synchronized into scientific research plan ,if necessary, the school can give the necessary capital investment; an annual appraisal acceptance should be organized, outstanding audio-visual materials, and multimedia course ware should be treated equally according to text materials and publications within a certain range; identification 
results should be served as the important basis of promotion rank to teachers and professional and technical personnel.

\section{The study of modern educational technology hot spots to provide technical support beam sea for teaching modern.}

With multimedia, simulation, network technology into the teaching practice, scientific system of modern educational technology rapidly formed, causing the teaching theory and teaching practice deep reforms. To give teaching concepts, teaching methods and teaching organization a profound influences of the other aspects. Educational technology workers have to face this new situation suddenly, surround this hot spot around the modern educational technology research, seize the opportunity to meet the challenges and promote the teaching of modern raise good technical support.

\section{Efforts to achieve the optimization of teaching}

Modern educational technology goal is to achieve optimal teaching. In this regard we must have a clear understanding of it, rather than the mention of modern educational technology to blind pursuit of advanced equipment, and even that only computer is the main indicator of educational technology, to engage in the computer will not engage in modern educational technology, completely ignored many development and application of traditional technologies. Of course, the new media appeared, our educational technology workers spend more energy to research and development, so that play a benefit in teaching as soon as possible. However, only the pursuit of a certain kind of media or preference, it is not the system, since any modern teaching media, has not been able in the future and can not get rid of the outstanding historical inheritance of traditional media, the degree of modernization in all media is not entirely equal to teaching effectiveness. To optimize teaching must focus on teaching objectives, teaching content and teaching objects and the teaching environment, we want to see whether favorable deepen students 'understanding of teaching content; whether it helps to mobilize the students' interest in learning; whether it helps expand the knowledge capacity; whether it helps to improve the teaching speed and save hours; whether it helps teachers to teach and students to learn; whether it is potential of using minimum investment for maximum efficiency, rather than one-sided pursuit of diversification of the media, the degree of modernization.

\section{Carrying out extensive multimedia teaching}

In the fierce competition in the survival of the fittest is inevitable, the goal of modern educational technology to optimize teaching first, and actively explore new media technology, rather than "rigid, inert", otherwise you will naturally lose the value of existence. Since formal traditional teaching methods alone are far behind the pace of teaching reform, and actively promote to be engaged in more multimedia teaching in the institutions (or a combination of multimedia teaching), and the establishment of various disciplines classroom. These properties of different teaching media combination has been optimized to lose weaknesses in teaching, interactive use, to achieve dynamic and static, audio-visual integration, and strive to make learning content changes abstract to intuitive, stiff to vivid, difficulty to simplify. It will play an active role in the change of modern teaching concept and improvement of the quality of teaching. With the development of multimedia computers, it has a variety of media information centralized control, unified management functions. In the process of teaching, it can not only put the reality of things on the screen rich unfolded, even those eyes not observe the grandeur and microscopic phenomena. It constitutes a new multimedia learning environment and greatly enrich and enhance the teaching performance and appeal. Modern education technical staff and educators, they must master the 
modern computer - based educational technology, especially multimedia technology based on knowledge and skills. And on the basis of ideas and teaching methods of modern education, and actively develop multimedia course ware to fit teaching objectives and teaching environment.

\section{Actively explore new technology network teaching}

In recent years a network of teaching as a new technology has been developed, which uses computer technology, network technology, information technology and multimedia technology for a system of modern teaching and learning activities. Its greatest feature is its openness and cross-boundary nature. It can achieve a wider range of information resources sharing, students don't limited in time and space constraints. They can browse to the military and civilian, at home and abroad and the professional information through the network, understanding discipline knowledge of the latest developments and cutting-edge. And the students from different institutions can elective courses from different school, which will greatly mobilize students' learning initiative, enthusiasm and creativity. Network teaching is the basic direction of the current and future development of educational technology.Currently, the institutions have set up campus network systems use more advanced technology to achieve a broadband network, fully support the application of multimedia network, providing teaching modern with a flow of information highway. But to ensure that the "road car", "stock car", it is imperative to keep up with application development, such as actively accelerate educational software, construction management software, information consulting and other online teaching resource library, and continually enrich and update information, and let the campus network broadband resources are effectively utilized. In particular, according to the modern integrate ideas, establishing multidimensional information integrate ware, using a combination of product items online education platform. That is the modern educational technology workers in research and development of another new topic.

\section{References}

1. Chen Yunhong. A Research on the Educational Technology Ability Standard of Military Academy Teachers. The Fourth Military Medical University, 2008(4).

2. Yang Gengyu. Applying Modern Educational Technology to Promote Education Modernization. Meitan Higher Education, 2001(1).

3. Chang Jing. Consideration on Teaching Management in the Process of Educational Technique Modernization. Journal of Shangdong Youth Administrator College, 2010(1).

4. Li Jianqing. Strengthening the Construction of Modern Education Technology, Advancing the Modernization of School Education. Journal of Jiangxi Administration Institute, 2009(S2).

5. Chen Longquan, Zhang Changhui. Modern Educational Technology and the Modernization of Class Teaching. Journal of Chengdu Education Institute, 2001(3). 